\title{
Spark Plasma Sintering of Ultrafine YSZ Reinforced Cu Matrix Functionally Graded Composite
}

\author{
Jafar Mirazimi $^{1} \cdot$ Parvin Abachi $^{1} \cdot$ Kazem Purazrang $^{1}$
}

Received: 1 May 2016/Revised: 14 August 2016/Published online: 8 November 2016

(C) The Chinese Society for Metals and Springer-Verlag Berlin Heidelberg 2016

\begin{abstract}
Copper matrix composites have received more attentions as possible candidate for thermal and electrical conductive materials to be used in electrical contact applications. In this study, five-layered $\mathrm{Cu} / \mathrm{YSZ}$ (yttria-stabilized zirconia) functionally graded material (FGM) and copper matrix composite specimens containing 3 and 5 vol\% YSZ particles plus pure $\mathrm{Cu}$ specimen were synthesized using powder metallurgy (PM) route and spark plasma sintering (SPS) consolidation process. The microstructural and some physical, mechanical features of all specimens were characterized. Microscopic examinations showed that ultrafine YSZ particles were distributed in the copper matrix almost homogeneously. An appropriate interface was observed at each layer of FGM. The density measurement indicated that the graded structure of the composite could be well densified after the SPS process. The microhardness values of various layers of $\mathrm{Cu} /$ YSZ FGM specimen were gradually altered from 56.3 (pure copper side) to $75.2 \mathrm{HV}$ (Cu-5 vol\% YSZ side). The increase of YSZ content resulted in a decrease in electrical conductivity. Additionally, thermal conductivity of Cu/YSZ FGM specimen $[308.0 \mathrm{~W} /(\mathrm{m} \mathrm{K})]$ was determined to be higher than that of the $\mathrm{Cu}-5 \mathrm{vol} \% \mathrm{YSZ}$ composite specimen [260.7 W/ $(\mathrm{m} \mathrm{K})]$. Accordingly, it can be concluded that the Cu/YSZ FGM can be a good candidate for the electrical applications, like sliding electrical contacts, where different material characteristics in the same component are required.
\end{abstract}

\section{KEY WORDS: Functionally graded material (FGM); Spark plasma sintering (SPS); Composite;} Microstructure; Interface

\section{Introduction}

It is well known that the pure copper has poor mechanical properties and high thermal expansion coefficient [1-4]. Therefore, one of the potential solutions for these drawbacks is the incorporation of a reinforcement element, which results in copper matrix composite as a by-product [5-8]. Metal matrix composites (MMCs), and in particular,

Available online at http://link.springer.com/journal/40195.

Jafar Mirazimi

jafarmirazimi@gmail.com

1 Department of Materials Science and Engineering, Sharif University of Technology, P.O. Box 11155-9466, Tehran, Iran copper matrix composites with high strength, high wear resistance, and good thermal and electrical conductivity fulfill the required criterion for various applications [1, 7]. Because of these interesting characteristics, these materials have a wide range of applications in various industries. Electrical contacts, heat sinks, high performance switches, and spot welding electrodes are the frequent usage cases of these applications [1-3, 9-13].

Nowadays, it is well known that by proper reinforcement selection, better properties for MMCs could be provided. Considering this comment, a variety of particulate ceramic materials like $\mathrm{Al}_{2} \mathrm{O}_{3}$ [4, 6, 13-15], $\mathrm{SiC}$ [12], $\mathrm{Cu}_{2} \mathrm{O}$ [16], and $\mathrm{TiB}_{2}$ [8] have been utilized to reinforce the copper matrix. The usage of above reinforcements has led to the enhancement of mechanical properties, which have been reported by researchers cited above. The major 
necessities for the ceramic particles as a reinforcement include: no solubility in the copper matrix, high interfacial energy of the particle-matrix interface, and as low as coefficient of thermal expansion (CTE) mismatch between matrix and reinforcement [4]. Ultrafine yttria-stabilized zirconia (YSZ) powder particles due to high strength and stiffness, high melting temperature and relatively good electrical property may fulfill some of aspects mentioned above [17]. However, because of the inherently different CTE and modulus of elasticity between zirconia and copper, it often brings failures of the materials when high residual thermal stresses are introduced at the interface under high-heat loads [18]. Furthermore, it is clear that with increasing of reinforcement content, the thermal and electrical conductivity of obtained composite decreases considerably. In order to overcome these drawbacks, an alternative design conception deals with a functionally graded material (FGM).

FGMs are inhomogeneous or generally two-component composite materials, in which the structure and/or composition changes continuously as a function of position [19]. Hence, FGMs have attracted considerable attention, due to their unique performance, sophisticated designation, and great potential in engineering applications $[19,20]$. Therefore, the main idea in this study is the producing of $\mathrm{Cu} / \mathrm{YSZ}$ FGM by applying a modern sintering technique.

Several different methods have been reported for the metal-based FGMs fabrication [21]. Centrifugal casting [22, 23], powder metallurgy (PM) [18, 20, 24-26], and microwave heating of multilayer powders compositions [27] are the most important of them. In all cases, the main problem is to reduce the residual thermal stresses in the FGM structures [27]. However, the PM is a relatively simple and widely used technique that allows one to accurately control composition [26]. Production of FGM by powder metallurgical process involves the sintering of the mixture of metallic and filing powders [25]. Among the various methods of sintering, in recent years, spark plasma sintering (SPS) as a popular sintering technique has been widely used in fabricating ceramics, cermet, metals, hard materials, composite materials, and FGMs [18]. The fundamental of this sintering technique has been described comprehensively in references [28, 29]. Short processing time, improved microstructure, and fully dense products are some characteristics of SPS prominent [14, 28, 29]. Referring to results of some researchers on Ti-based alloys and composites, it has been proved that SPS has advantages of fabricating ultrafine grained metallic materials with higher mechanical properties [30-32]. Moreover, researchers have utilized the SPS process for the fabrication of $\mathrm{W} / \mathrm{Cu}$ [18]; $\mathrm{Al} / \mathrm{SiC}$ [33]; Cu/diamond [23]; and carbon nanotube-nanoSiC/Al [34] FGMs. A short review on SPS of FGMs has been also given by Sobczak and Drenchev [35].

The present study aims to fabricate five-layered (pure $\mathrm{Cu}, \mathrm{Cu}-2$ vol\% YSZ, Cu-3 vol\% YSZ, Cu-4 vol\% YSZ, and $\mathrm{Cu}-5$ vol\% YSZ) ultrafine YSZ reinforced copper matrix (designated as $\mathrm{Cu} / \mathrm{YSZ}$ FGM) and compare its microstructure and some physical, mechanical features with pure $\mathrm{Cu}, \mathrm{Cu}-3$ vol\% YSZ and $\mathrm{Cu}-5$ vol\% YSZ composite specimens.

\section{Materials and Experimental Procedure}

The copper powder (with purity of $99.8 \mathrm{wt} \%$ and particle size mostly less than $63 \mu \mathrm{m}$, Merck, Germany) and YSZ powder $\left(\mathrm{ZrO}_{2}-7.5 \mathrm{wt} \% \mathrm{Y}_{2} \mathrm{O}_{3}, \phi<200 \mathrm{~nm}\right.$, Sulzer-Metco, USA) were used as raw materials. The size and the morphology of powder particles were characterized by field emission scanning electron microscopy (FE-SEM, Mira3, TESCAN). For homogeneous distribution of specified volume percentages of ultrafine YSZ powder particles in copper matrix (i.e., 0, 2, 3, 4 and 5 vol\%), a Turbula mixer (Turbula TC2, Willy Bachofen) was used. Before mixing, de-agglomeration of YSZ particles was performed using a ultrasonic device with proper quantity of acetone as dispersing agent. For production of $\mathrm{Cu} / \mathrm{YSZ}$ FGM specimen, the mixed powders were stacked layer-by-layer into the steel die with $30 \mathrm{~mm}$ in diameter and then were cold prepressed at the load of $20 \mathrm{MPa}$. Figure 1a shows the schematic illustration of $\mathrm{Cu} / \mathrm{YSZ}$ FGM specimen, which consists of five layers varying in volume percentage of YSZ powder particles along the thickness, and Fig. 1b shows the micrograph of prepared $\mathrm{Cu} / \mathrm{YSZ}$ FGM green compact.

The SPS system (SPS-20T-10, EFMPT Co., Ltd, China) was used for sintering and further consolidation of $\mathrm{Cu} / \mathrm{YSZ}$ FGM green compact. Thus, the green compact was accurately placed into the graphite die and then mounted to the SPS apparatus. The sintering temperature, holding time, applied pressure, and sintering atmosphere were selected as $720{ }^{\circ} \mathrm{C}, 5 \mathrm{~min}, 40 \mathrm{MPa}$, and $1.3 \times 10^{-2}$ torr, respectively. The heating rate was adjusted as high as $50{ }^{\circ} \mathrm{C} / \mathrm{min}$. At first, the value of uniaxial applied load was selected as $10 \mathrm{MPa}$ and after reaching $650{ }^{\circ} \mathrm{C}$, it increased to $40 \mathrm{MPa}$. Figure 2 illustrates the temperature and pressure profiles during the SPS process of the $\mathrm{Cu} / \mathrm{YSZ}$ FGM specimen. The values of these parameters were controlled and recorded at 1-min intervals via related equipment attached to SPS system. The voltage and amperage of pulsed direct current were in the range of 2-3 V and 1000-2000 A, respectively. The duration of each pulse in on and off conditions was 12 and $2 \mathrm{~ms}$, respectively. Figure 3 represents the macrograph of $\mathrm{Cu} / \mathrm{YSZ}$ FGM specimen after consolidation by SPS 


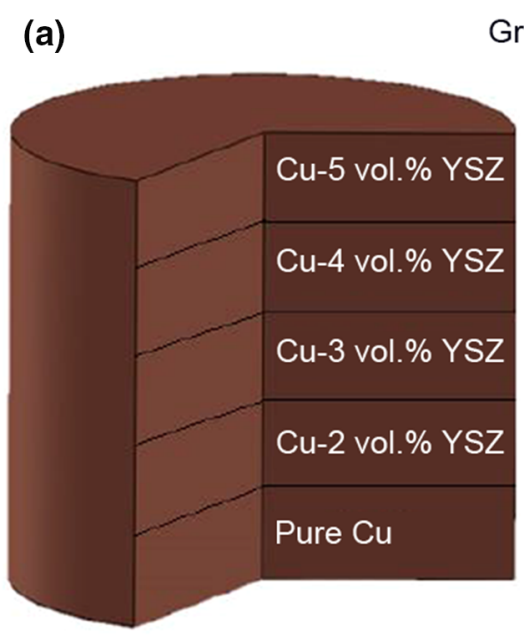

Green compact

(b)

Steel die

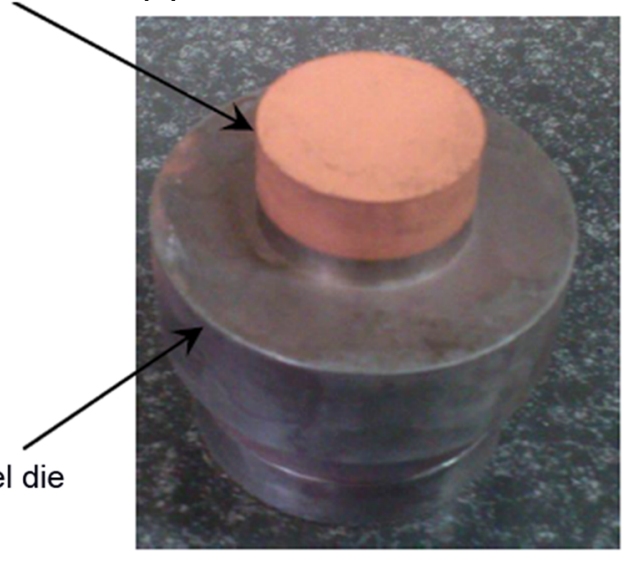

Fig. 1 a Schematic of Cu/YSZ FGM specimen, b macrograph of Cu/YSZ FGM green compact, which prepressed using steel die

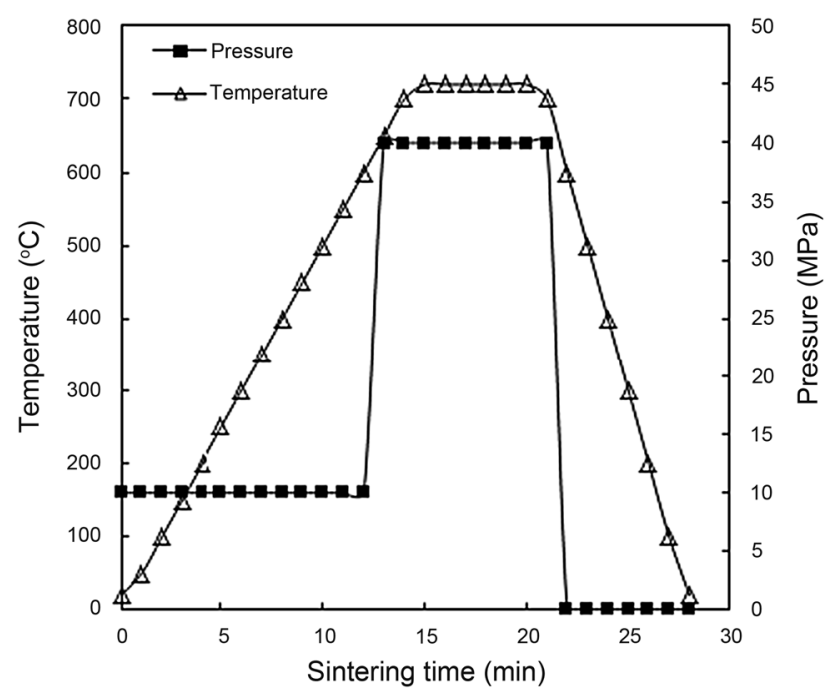

Fig. 2 Illustration of temperature and pressure profiles during the SPS process of the $\mathrm{Cu} / \mathrm{YSZ}$ FGM specimen. The sintering temperature, pressure and time are $720^{\circ} \mathrm{C}, 40 \mathrm{MPa}$ and $5 \mathrm{~min}$, respectively

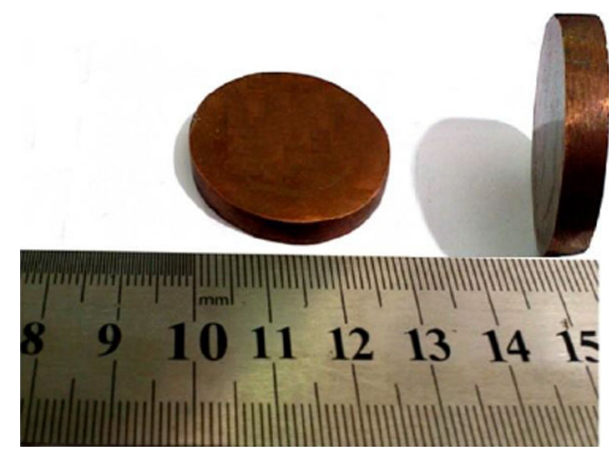

Fig. 3 Micrograph of Cu/YSZ FGM specimen after consolidation by SPS machine. Height and diameter are about 5 (each layer almost $1 \mathrm{~mm}$ ) and $30 \mathrm{~mm}$, respectively process. The height and diameter of specimen are almost 5 and $30 \mathrm{~mm}$, respectively.

In addition to $\mathrm{Cu} / \mathrm{YSZ} \mathrm{FGM}$, the $\mathrm{Cu}-\mathrm{YSZ}$ composite specimens having 0 (pure $\mathrm{Cu}$ ), 3, and 5 vol\% YSZ with $\sim 5 \mathrm{~mm}$ homogeneous cross section and $\sim 30 \mathrm{~mm}$ diameter were also produced in same procedure.

The microstructural analysis was carried out by optical microscopy and FE-SEM equipped with energy-dispersive $\mathrm{X}$-ray spectroscopy (EDS) after etching of the specimens with a mixture of $5 \mathrm{~g} \mathrm{FeCl}_{3}$ and $50 \mathrm{ml} \mathrm{HCl}$ in $100 \mathrm{ml}$ distilled water solution. The density of the specimens was determined using Archimedes method.

Electrical resistivity of all specimens was measured using a precise micro-ohmmeter (LCR-8110G, GWINSTEK), and then, the specific electrical resistivity of specimens was determined and converted to international annealed copper standard conductivity (IACS) unit according to ASTM B193 standard test method. Subsequently, the thermal conductivity of the specimens was calculated using Wiedemann-Franz law as fallows [13]:

$k / \sigma=L T$,

where $k$ is the thermal conductivity in $\mathrm{W} /(\mathrm{m} \mathrm{K}), T$ is the absolute temperature in $\mathrm{K}, \sigma$ is the electrical conductivity in $\Omega^{-1} \mathrm{~m}^{-1}$, and $L$ is the Lorenz number, equal to $2.45 \times 10^{-8} \mathrm{~W} \Omega / \mathrm{K}^{2}$.

Microhardness measurements were taken under a load of $0.5 \mathrm{~N}$ and loading time of $15 \mathrm{~s}$. For the Cu/YSZ FGM specimen, three measurements were taken on each layer.

\section{Results and Discussion}

Figure $4 \mathrm{a}, \mathrm{b}$ shows the morphology of copper and YSZ powder particles, respectively. The morphology of electrolytic copper powder particles is dendritic. However, 

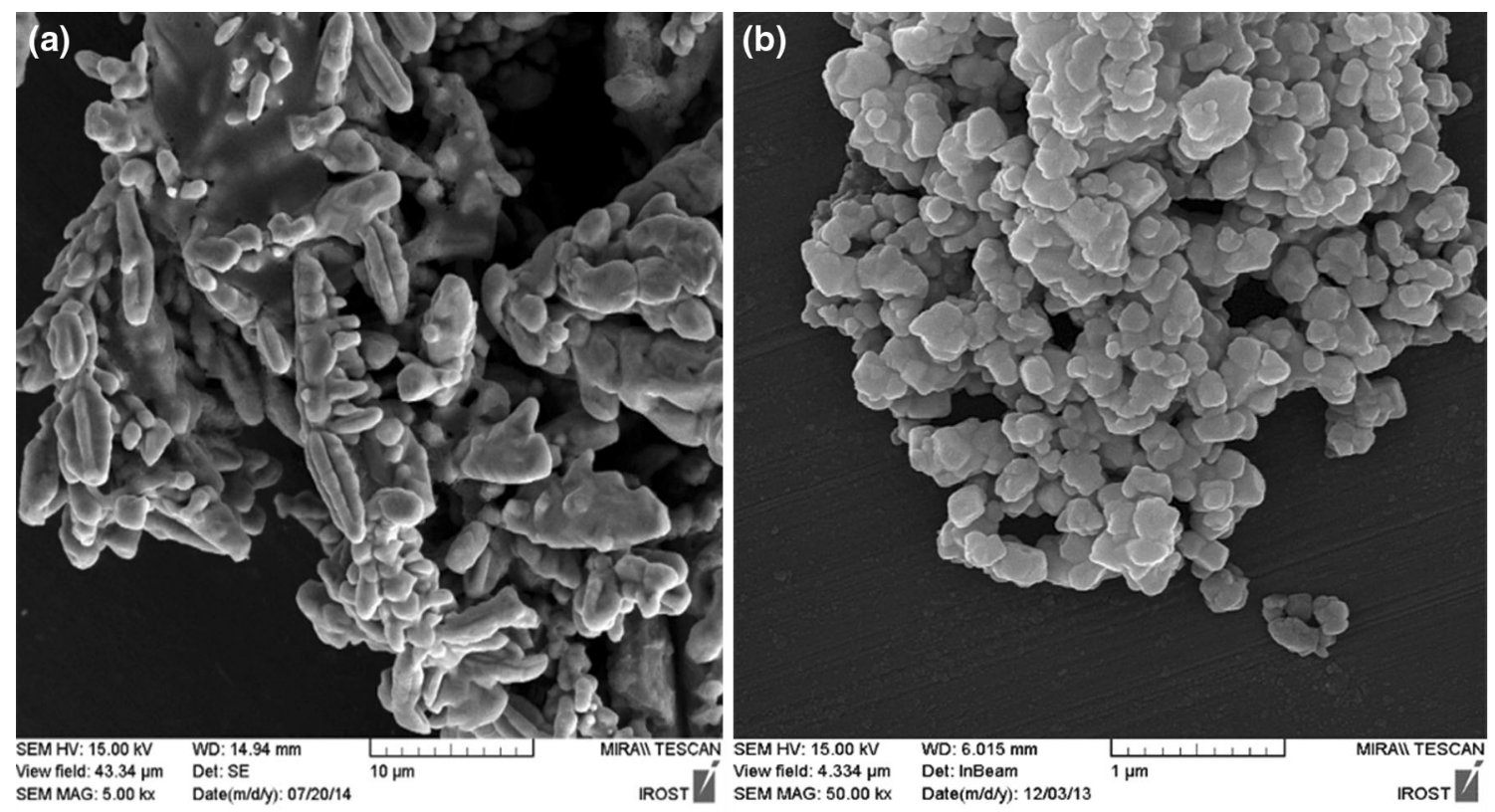

Fig. 4 FE-SEM micrographs of a as-received $\mathrm{Cu}, \mathbf{b}$ YSZ powder particles

YSZ particles are almost in polygonal shape with particle size of $\sim 200 \mathrm{~nm}$.

Figure 5 indicates the etched optical micrographs of individual cross section of composite specimens containing 0,3 , and 5 vol\% YSZ particles. As shown in Fig. 5a, it is clear that the size of $\mathrm{Cu}$ grains is about $40-50 \mu \mathrm{m}$. Figure $5 \mathrm{~b}, \mathrm{c}$ shows that the grain size of copper matrix decreases with increasing particles content. In fact, the movement of the grain boundaries and consequently grain growth could be inhibited by reinforcing particles [36].

Figure 6 shows the microstructure of different regions of $\mathrm{Cu} / \mathrm{YSZ}$ FGM specimen. Back scatter electrons (BSE) are used to detect contrast between areas with different chemical compositions. Since heavy phases backscatter electrons more strongly than light ones, they appear to be brighter in the FE-SEM image. In the previous author's work [37], brighter and darker regions correspond to $\mathrm{Cu}$ (heavy phase) and YSZ (lighter phase) particles, respectively. Evidently, the composite layers were successfully consolidated using SPS technique, and no considerable porosity was seen at the interface of layers. Additionally, an efficient and smooth interface can be seen between subsequent layers. According to Fig. 6a, b, which correspond to the interfaces between pure $\mathrm{Cu}$ and subsequent layers $(\mathrm{Cu}-\mathrm{Cu}-2 \mathrm{vol} \% \mathrm{YSZ}$ and $\mathrm{Cu}-4$ vol\% YSZ, Cu-5 vol\% YSZ layers), it seems that there is a good interfacial bonding without any crack between the layers. As it can be seen in Fig. 6a-e, almost proper distribution of YSZ reinforcement particles (especially in layers with low content of particles) in copper matrix is achieved. However, by increasing the YSZ particles content, the agglomeration has been intensified and the size of particles is beyond of the original one.
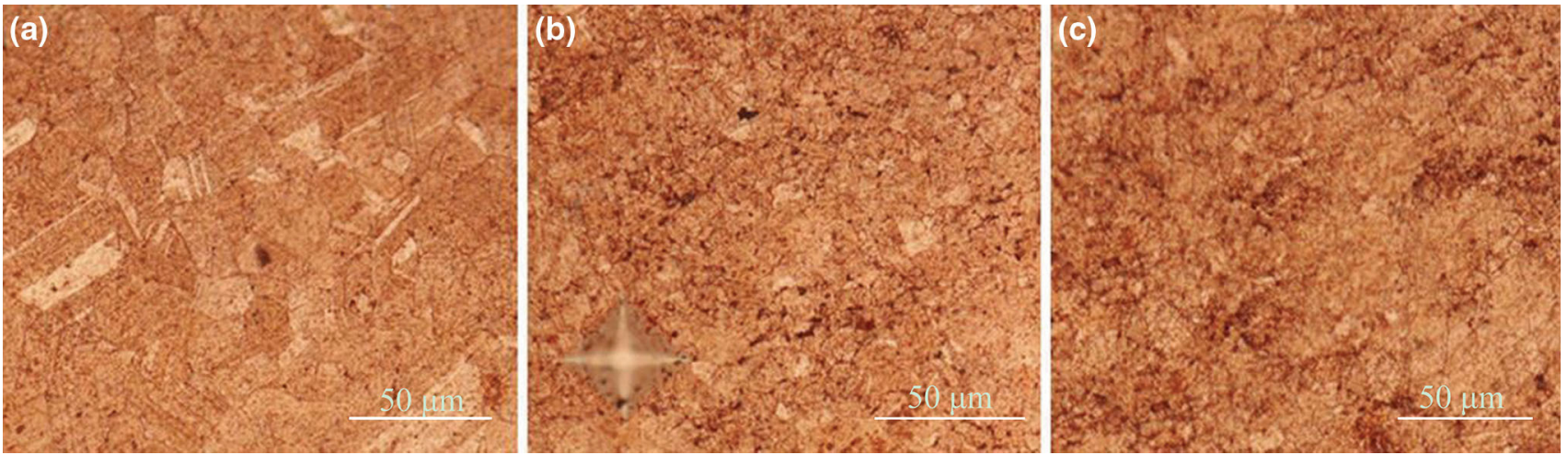

Fig. 5 Optical micrographs of a pure $\mathrm{Cu}$ (0 vol\% YSZ), b Cu-3 vol\% YSZ, c Cu-5 vol\% YSZ composite specimens 


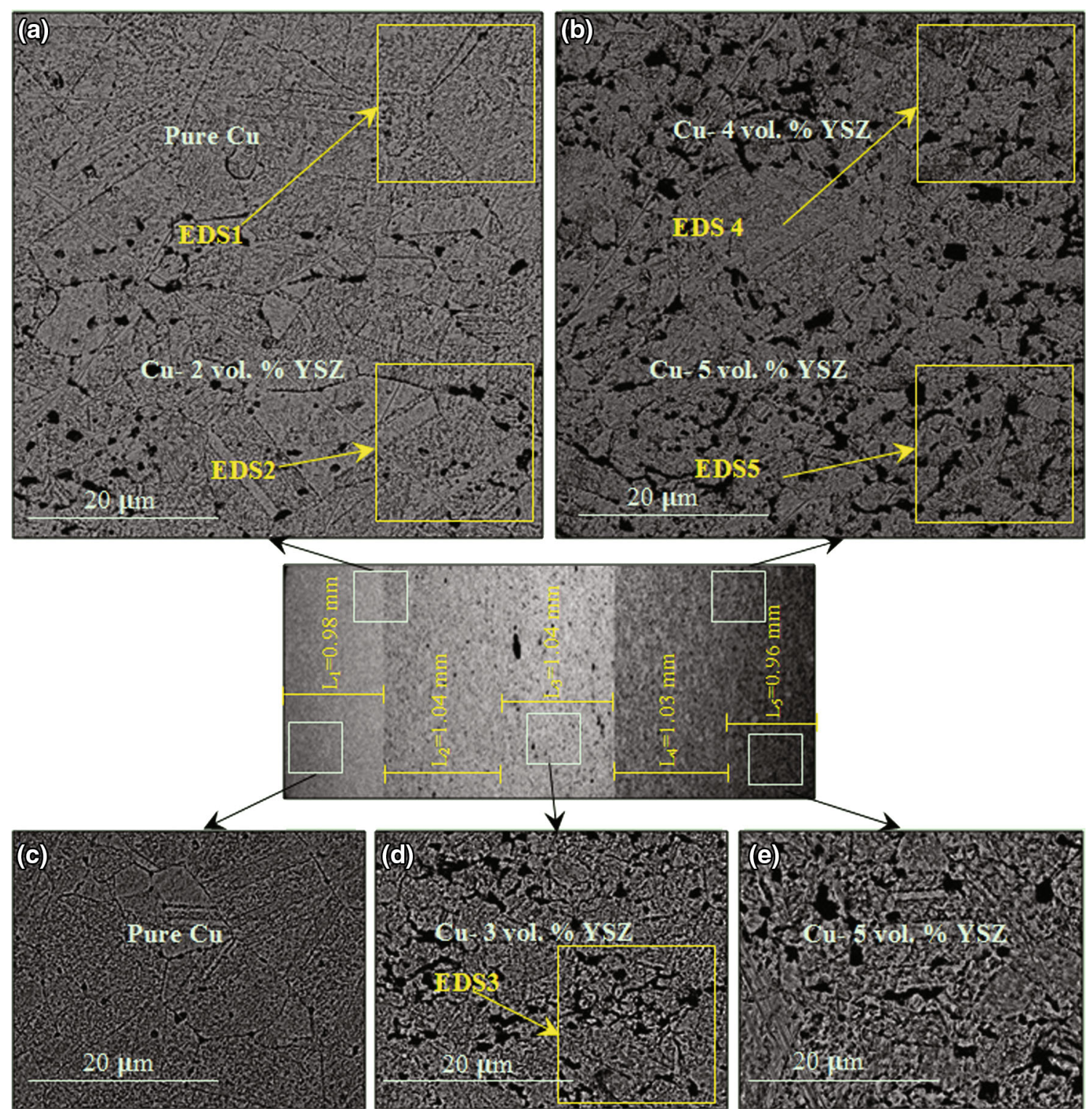

Fig. 6 FE-SEM micrographs of Cu/YSZ FGM (central image): a interface of pure $\mathrm{Cu} / \mathrm{Cu}-2$ vol\% YSZ, $\mathbf{b}$ interface of $\mathrm{Cu}-4 \mathrm{vol} \% \mathrm{YSZ}$ and $\mathrm{Cu}-5$ vol\% YSZ layers, c individual pure $\mathrm{Cu}, \mathrm{Cu}-3$ vol\% YSZ, $\mathrm{Cu}-5$ vol\% YSZ graded layers

According to Ref. [12], the homogeneous distribution of reinforcement particles in the matrix can significantly lead to mechanical, electrical, and thermal properties improvement in composite materials.

To examine more YSZ particles distribution in copper matrix, the EDS surface scanning was also carried out on specified areas of different layers of $\mathrm{Cu} / \mathrm{YSZ}$ FGM specimen. The areas are indicated in Fig. 6, and the results are given in Table 1. Clearly, the content of $\mathrm{Zr}$ and $\mathrm{Y}$ increases with increasing volume percentage of YSZ.

Table 2 shows some physical and mechanical properties of $\mathrm{Cu} / \mathrm{YSZ}$ FGM and composite specimens. In calculating the relative density of specimens, theoretical density of copper and YSZ materials was taken as 8.96 [16] and
Table 1 EDS analysis results on different layers of $\mathrm{Cu} / \mathrm{YSZ}$ FGM specimen

\begin{tabular}{lcccc}
\hline FGM layer & \multicolumn{4}{l}{ Elements (wt\%) } \\
\cline { 2 - 5 } & $\mathrm{Cu}$ & $\mathrm{Zr}$ & $\mathrm{Y}$ & $\mathrm{O}$ \\
\hline Pure Cu (EDS1) & 100.00 & 0.00 & 0.00 & 0.00 \\
$\mathrm{Cu}-2$ vol\% YSZ (EDS2) & 96.5 & 1.40 & 0.69 & 1.37 \\
$\mathrm{Cu}-3$ vol\% YSZ (EDS3) & 94.70 & 4.16 & 0.41 & 0.73 \\
$\mathrm{Cu}-4$ vol\% YSZ (EDS4) & 91.11 & 6.21 & 0.70 & 1.98 \\
$\mathrm{Cu}-5$ vol\% YSZ (EDS5) & 89.57 & 6.61 & 0.81 & 3.01 \\
\hline
\end{tabular}

$6.05 \mathrm{~g} / \mathrm{cm}^{3}$ [38], respectively. The relative density values show that the sintering by SPS system has led to the considerable consolidation of specimens, as mentioned by 
Table 2 Relative density, Vickers microhardness, specific electrical resistivity, electrical and thermal conductivity values of pure Cu, Cu-YSZ composite and $\mathrm{Cu} / \mathrm{YSZ}$ FGM specimens

\begin{tabular}{llllll}
\hline Material & $\begin{array}{l}\text { Relative density } \\
(\%)\end{array}$ & $\begin{array}{l}\text { Microhardness } \\
(\mathrm{HV})\end{array}$ & $\begin{array}{l}\text { Specific electrical } \\
\text { resistivity }(\mu \Omega \mathrm{cm})\end{array}$ & $\begin{array}{l}\text { Electrical conductivity } \\
(\text { IACS \%) }\end{array}$ & $\begin{array}{l}\text { Thermal conductivity } \\
(\mathrm{W} /(\mathrm{m} \mathrm{K}))\end{array}$ \\
\hline Pure Cu & 99.33 & 48.6 & 1.84 & 93.70 & 397 \\
$\mathrm{Cu}-3$ vol\% YSZ & 96.73 & 80.7 & 2.45 & 70.37 & 298 \\
$\mathrm{Cu}-5$ vol\% YSZ & 95.4 & 87 & 2.80 & 61.57 & 260.7 \\
$\mathrm{Cu} /$ YSZ FGM & 97.3 & $56.3-75.2$ & 2.37 & 72.74 & 308 \\
\hline
\end{tabular}

others $[4,16,36]$. In this study, the maximum densification has obtained for pure copper due to its formability. Densification mechanisms of spark plasma sintered pure copper have been well described by Diouf and Molinari [39] and Zhang et al. [40]. As they claimed, rearrangement, localized deformation, bulk plastic deformation, and finally mass transport phenomena are the key mechanisms of copper sintering via SPS. For the composite specimens, a slight decrease in densification is seen with increasing YSZ content. In fact, the presence of hard ceramic particles, acting as diffusion barrier can prevent the copper atoms easily from filling out the interfaces between $\mathrm{Cu}-\mathrm{Cu}$ and $\mathrm{Cu}-\mathrm{YSZ}$ particles and thus reduces compressibility [12]. However, the density of the $\mathrm{Cu} / \mathrm{YSZ}$ FGM specimen is higher than those of the composite specimens while lower than that of pure $\mathrm{Cu}$. This can be explained by the lower density of YSZ in comparison with copper [13].

The Vickers microhardness of pure $\mathrm{Cu}$ has been considerably increased by addition of 5 vol\% ceramic particles (Table 2). It dates back to this fact that the presence of YSZ particles can impede dislocations movement according to Orowan mechanism and thus increase the hardness of the composite specimens. Figure 7 represents the microhardness profile of grade layers of $\mathrm{Cu} / \mathrm{YSZ}$ FGM specimen. According to Table 2 and Fig. 7, the microhardness values of various layers of $\mathrm{Cu} / Y S Z$ FGM specimen have gradually altered from 56.3 (pure copper side) to $75.2 \mathrm{HV}$ (composite side). In addition to microhardness enhancement, the presence of YSZ particles causes an effective improvement in the wear resistance of described composite specimens [37].

The reference value for specific electrical resistivity of pure copper metal is $1.7241 \mu \Omega \mathrm{cm}$ [7]. However, this value has increased to $1.84 \mu \Omega \mathrm{cm}$ for spark plasma sintered pure copper in this work, as it can be seen in Table 2. This could be mainly due to the remained pores and matrix grain refinement. Moreover, the addition of 5 vol\% YSZ particles to copper has induced the increase of specific electrical resistivity up to almost $52 \%$. This is equivalent to a decrease of electrical conductivity from 93.70 to 61.57 (IACS \%), as listed in Table 2. The influence of ceramic

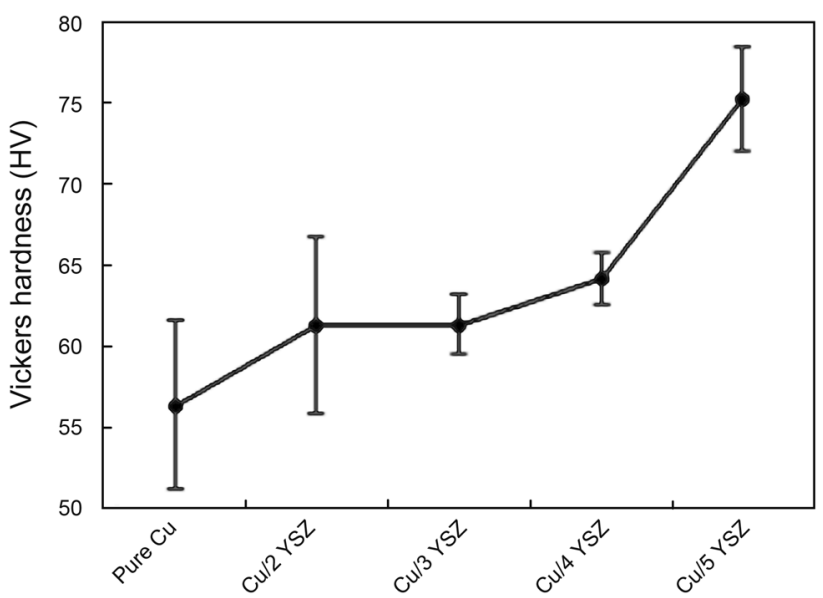

Fig. 7 Vickers microhardness of various layers in $\mathrm{Cu} / \mathrm{YSZ}$ FGM specimen produced by SPS process

particles with low electrical conductivity and thermal residual stresses due to CTE mismatch between matrix and reinforcement should be considered as further reasons for this increment. Commonly, higher density would lead to a lower electrical resistivity. SPS has been used extensively over the past years to consolidate wide range of materials including nanocomposites [43]. It has been shown that this sintering method, in comparison with conventional sintering method, is more effective for obtaining fully dense materials with preserved nanostructure features [18, 19, 30-32, 34, 36-39, 41-43]. Kim et al. [41] has used SPS to obtain a highly conductive $\mathrm{Cu}-4.5$ vol\% $\mathrm{TiB}_{2}$ nanocomposite with $82 \%-87 \%$ IACS conductivity. Kwon et al. [34] reported that the increase of $\mathrm{TiB}_{2}$ content from 2.5 up to $7.5 \mathrm{wt} \%$ in $\mathrm{Cu}-\mathrm{TiB}_{2}$ nanocomposites prepared by SPS resulted in a 1.5-fold increase in yield strength, tensile strength, and hardness and fivefold increase in wear resistance with only $10 \%$ decrease in conductivity. Nevertheless, the research results on $\mathrm{Cu}-\mathrm{Ti}_{3} \mathrm{SiC}_{2}$ by $\mathrm{Ngain}$ et al. [42] indicated that the composites prepared by SPS sintering at $950{ }^{\circ} \mathrm{C}$ have higher density and mechanical properties when compared with the composites prepared by warm compaction forming and at $750{ }^{\circ} \mathrm{C}$, but their electrical resistivity values are very close to each other and 
even higher. The most probable reason for this peculiar phenomenon (usually higher density would lead to a lower resistivity) is that the reinforcing particles in $\mathrm{Cu}-\mathrm{Ti}_{3} \mathrm{SiC}_{2}$ composites are not stable above $800{ }^{\circ} \mathrm{C}$. The research results by Khaloobagheri et al. [44] on copper matrix nanocomposite reinforced with $1-5 \mathrm{wt} \%$ yttria-stabilizedzirconia showed that the maximum electrical conductivity of test materials ranged from $88.0 \%$ IACS to $59.7 \%$ IACS. This indicates that synthesize of these composites by mechanical alloying, cold press and subsequent sintering, as an alternative to SPS, leads to a slightly more decrease in electrical conductivity.

In the investigated $\mathrm{Cu} / \mathrm{YSZ}$ FGM specimen in this research, the existence of pure $\mathrm{Cu}$ layer and consequently easy movement of electrons through this layer, the increment of electrical resistivity is limited.

Based on Wiedemann-Franz law, Eq. (1), and ASTM B193 standard test method, thermal conductivity of pure copper was obtained to be $\sim 397 \mathrm{~W} /(\mathrm{m} \mathrm{K})$ at room temperature. As can be seen in Table 2, thermal conductivity of composite specimens decreases with the increase of YSZ content. The heat transfer in metallic materials mainly results from the movement of the free electrons, and therefore, the existence of the pores can intensify the scattering of electrons and prevent the linear transition of the free electrons [18]. However, as described above, due to easily movement of free electrons through pure $\mathrm{Cu}$ layer, the $\mathrm{Cu} / \mathrm{YSZ}$ FGM specimen in overall exhibits better thermal conductivity than $\mathrm{Cu}-\mathrm{YSZ}$ composite specimens.

\section{Conclusion}

The bulk homogeneous $\mathrm{Cu}-\mathrm{YSZ}$ composites and $\mathrm{Cu} / \mathrm{YSZ}$ FGM containing 5 layers were produced by SPS process. Microstructural observations indicated a relatively proper distribution of YSZ ultrafine particles in $\mathrm{Cu}$ matrix. However, better control of agglomeration could be the subject of on-going investigations. Additionally, a lack of any crack and delamination at the interface of composite layers were indication of good interfacial bonding between the layers. Relative density results revealed the possibility of excellent densification of graded structure composites during SPS process. Based on the results, the mean Vickers microhardness of $\mathrm{Cu} / \mathrm{YSZ}$ FGM specimen is comparable with microhardness of homogeneous composite specimens, while the FGM specimen showed better thermal conductivity than individual composite specimens. Accordingly, it can be concluded that the Cu/YSZ FGM can be a good candidate for the electrical contact applications, where higher hardness plus wear resistance at the surface and desired electrical conductivity at the bulk of component are required.

\section{References}

[1] I. Celikyurek, N.O. Korpe, T. Olcer, R. Gürler, J. Mater. Sci. Technol. 27, 937 (2011)

[2] F. Akhtar, S.J. Askari, K. Ali Shah, X. Du, S. Guo, Mater. Charact. 60, 327 (2009)

[3] S.C. Tjong, K.C. Lau, Mater. Lett. 43, 274 (2000)

[4] R. Ritasalo, X.W. Liua, O. Soderberg, A. Keski-Honkola, V. Pikanen, S.P. Hannula, Procedia Eng. 10, 124 (2011)

[5] M.R. Akbarpour, E. Salehi, F. Alikhani, Hesari. Ceram. Int. 40, 951 (2014)

[6] W. Zein Eddine, P. Matteazzi, J.P. Celis, Wear 297, 762 (2013)

[7] N. Selvakumar, S.C. Vettivel, Mater. Des. 46, 16 (2013)

[8] J.P. Tu, N.Y. Wang, Y.Z. Yang, W.X. Qi, F. Liu, X.B. Zhang, H.M. Lu, M.S. Liu, Mater. Lett. 52, 448 (2002)

[9] B.M. Girish, B.R. Basawaraj, B.M. Satish, D.R. Somashekar, Int. J. Compos. Mater. 2, 37 (2012)

[10] T. Larionova, T. Koltsova, Y. Fadin, O. Tolochko, Wear 319, 118 (2014)

[11] J. Zhang, L. He, Y. Zhou, Scr. Mater. 60, 976 (2009)

[12] G. Celebi Efe, M. Ipek, S. Zeytin, C. Bindal, Compos. Pt. B-Eng. 43, 1813 (2012)

[13] A. Fathy, O. El-Kady, Mater. Des. 46, 355 (2013)

[14] C.A. Leon, G. Rodriguez-Ortiz, M. Nanko, E.A. Aguilar, Powder Technol. 252, 1 (2014)

[15] A. Fathy, F. Shehata, M. Abdelhameed, M. Elmahdy, Mater. Des. 36, 100 (2012)

[16] R. Ritasalo, M.E. Cura, X.W. Liu, Y. Ge, T. Kosonen, U. Kanerva, O. Soderberg, S.P. Hannula, Compos. Pt. A-Appl. Sci. Manuf. 45, 61 (2013)

[17] C.L. Yang, H.I. Hsiang, C.C. Chen, Ceram. Int. 31, 297 (2005)

[18] X. Tang, H. Zhang, D. Du, D. Qu, C. Hu, R. Xie, Y. Feng, Int. J. Refract. Met. Hard Mater. 42, 193 (2014)

[19] S. Wei, Z.H. Zhang, X.B. Shen, F.C. Wang, M.Y. Sun, R. Yang, S.K. Lee, Comput. Mater. Sci. 60, 168 (2012)

[20] S. Gholami Shiri, P. Abachi, K. Pourazarang, M. Mohammad Rahvard, Trans. Nonferrous Met. Soc. China 25, 863 (2015)

[21] T.P.D. Rajan, B.C. Pay, Acta Metall. Sin. (Engl. Lett.) 27, 825 (2014)

[22] H. Sato, Y. Inaguma, Y. Watanabe, Mater. Sci. Forum 638-642, 2160 (2010)

[23] T. Kunimine, M. Shibuya, H. Sato, Y. Watanabe, J. Mater. Process. Technol. 214, 294 (2015)

[24] R.X. Guo, F. Yan, H.T. Xia, Adv. Mater. Res. 378-379, 47 (2012)

[25] M.M. Nemat-Alla, M.M. Ata, M.R. Bayoumi, W.K. Eldeen, Mater. Sci. Appl. 2, 1708 (2011)

[26] S. Yang, H. Kim, C.S. Lee, Ceram. Int. 39, 93 (2013)

[27] Y. Meng, J. Zhang, C. Duan, C. Chen, X. Feng, Y. Shen, Adv. Powder Technol. 26, 392 (2015)

[28] Z.H. Zhang, Z.F. Liu, J.F. Lu, X.B. Shen, F.C. Wang, Y.D. Wang, Scr. Mater. 81, 56 (2014)

[29] M.S. Yurlova, V.D. Demenyuk, L.Y. Lebedeva, D.V. Dudina, E.G. Grigoryev, E.A. Olevsky, J. Mater. Sci. 49, 952 (2014)

[30] L.H. Liu, C. Yang, L.M. Kang, S.G. Qu, X.Q. Li, W.W. Zhang, W.P. Chen, Y.Y. Li, P.J. Li, L.C. Zhang, Sci. Rep. 6, 1 (2016)

[31] L.H. Liu, C. Yang, L.M. Kang, Y. Long, Z.Y. Xiao, P.J. Li, L.C. Zhang, Mater. Sci. Eng., A 650, 171 (2016)

[32] L.H. Liu, C. Yang, F. Wang, S.G. Qu, X.Q. Li, W.W. Zhang, Y.Y. Li, L.C. Zhang, Mater. Des. 79, 1 (2015)

[33] T. Rajan, R. Pillai, B. Pai, Mater. Charact. 61, 923 (2010)

[34] H. Kwon, M. Leparoux, A. Kawasaki, J. Mater. Sci. Technol. 30, 736 (2014)

[35] J.J. Sobczak, L. Drenchev, J. Mater. Sci. Technol. 29, 297 (2013) 
[36] K. Dash, B.C. Ray, D. Chaira, J. Alloys Compd. 516, 78 (2012)

[37] J. Mirazimi, P. Abachi, K. Purazrang, Trans. Nonferrous Met. Soc. China 26, 1745 (2016)

[38] D. Maeland, C. Suciu, I. Waernhus, A.C. Hahhmann, J. Eu. Ceram. Soc. 29, 2537 (2009)

[39] S. Diouf, A. Molinari, Powder Technol. 221, 220 (2012)

[40] Z.H. Zhang, F.C. Wang, L. Wang, S.K. Li, Mater. Sci. Eng., A 476, 201 (2008)
[41] J.S. Kim, D.V. Dudina, J.C. Kim, Y.S. Kwon, J.J. Park, C.K. Rhee, J. Nanosci. Nanotechnol. 10, 252 (2010)

[42] T.L. Ngain, W. Zheng, Y. Li, Mater. Int. 23, 70 (2013)

[43] N. Saheb, Z. Iqbal, A. Khalil, A.S. Hakeem, N. Al Aqeeli, T. Laoui, A. Al-Qutub, R. Kirchner, J. Nanomater. 2012, 18 (2012)

[44] M. Khaloobagheri, B. Janipour, N. Askari, Adv. Mater. Res. 829, 610 (2014) 